\title{
Studies on the mechanism of action of 6-mercaptopurine
}

\author{
Interaction with copper and xanthine oxidase \\ Ume KELA* and Rameshwar VIJAYVARGIYA \\ Department of Pharmacology, Mahatma Gandi Memorial Medical College, Indore-452001, India
}

(Received 15 September 1980/Accepted 20 October 1980)

\begin{abstract}
Interaction between 6-mercaptopurine, $\mathrm{Cu}^{2+}$ and the enzyme xanthine oxidase (EC 1.2.3.2) was examined. Whereas $\mathrm{Cu}^{2+}$ was found to inhibit the enzyme, 6-mercaptopurine could protect as well as reverse the eznyme inhibition produced by the metal ion. The formation of a complex between 6-mercaptopurine and $\mathrm{Cu}^{2+}$ seems to be responsible for the observed effect. Job's [(1928) Ann. Chem. 9, 113] method has shown the composition of the complex to be $1: 1$. The apparent stability constant ( $\log K$ value), as determined by Subhrama Rao \& Raghav Rao's [(1955) J. Sci. Chem. Ind. Res. 143, 2781, method is found to be 6.74. It is suggested that the formation of a stable complex between 6-mercaptopurine molecules and $\mathrm{Cu}^{2+}$ may be an additional mechanism of action of 6-mercaptopurine, particularly with reference to its anti-inflammatory properties.
\end{abstract}

Besides the major use of 6-mercaptopurine as an anti-neoplastic agent (Calabresi \& Parks, 1975), it has found additional application as an immunosuppressive (Hitchings \& Elion, 1963) and antiinflammatory drug (Page et al., 1962). Although the mechanism of its anti-neoplastic action (interfering with nucleic acid biosynthesis; Calabresi \& Parks, 1975) and of immunosuppression (inhibiting antibody production; Hitchings \& Elion, 1963) is well documented, the biochemical basis of its antiinflammatory activity in diseases such as hepatitis (Page et al., 1962), collagen diseases (Lorenzen \& Videbaek, 1965), ulcerative colitis (Bean, 1966) etc. is not very well explained by the described mechanisms of action.

One of the mechanisms underlying the antiinflammatory action of various drugs has in recent years been explained by the formation of their copper chelates (Elmes, 1974). However, no such information regarding the anti-inflammatory activity of 6-mercaptopurine being mediated through the formation of its copper chelate is available. Tissue and serum copper concentrations are known to be elevated in malignancy, as well as in inflammatory processes, and are an extremely sensitive indicator of these conditions (Hrgovcic et al., 1973). Moreover, a relationship between copper concentration and activity of the disease and the effectiveness of

\footnotetext{
* Present address and address for reprints: c/o Scientific Instruments (Indore) Private Limited, B-14 Pologround Industrial Estate, Indore-452003, India.
}

the therapy exists. High copper concentrations are observed in active disease, diminishing with the abatement of the disease in response to the therapy (Hrgovcic et al., 1973; Fleming et al., 1974). Furthermore it is also reported that the activity of xanthine oxidase (xanthine :oxygen oxidoreductase, EC 1.2.3.2), the enzyme responsible for the metabolism of 6-mercaptopurine, is decreased in neoplastic disorders (Prajda et al., 1976). The altered activity of this enzyme appears to be characteristic of neoplastic transformations (Weber, 1973). $\mathrm{Cu}^{2+}$, in addition, is known to be a potent inhibitor of xanthine oxidase (Bergel \& Bray, 1959).

These facts indicate the possibility that an interrelationship between the action of 6-mercaptopurine, $\mathrm{Cu}^{2+}$ and xanthine oxidase could exist under the conditions cited above. In the present study, therefore, we have tried to examine the interaction between them, since no such information is available.

\section{Materials and methods}

\section{Chemicals}

Xanthine, 6-mercaptopurine and calcium phosphate gel were obtained from Sigma. 2,3,5-Triphenyltetrazolium chloride and $\mathrm{CuSO}_{4}$ were purchased from B.D.H. All other chemicals were of analytical grade.

\section{Preparation of xanthine oxidase}

Milk xanthine oxidase was prepared by the 
method of Massey et al. (1969). The final purification of the enzyme on $\mathrm{Ca}_{3} \mathrm{PO}_{4}$ gel was done by the 'Alternate step 3' (Massey et al., 1969). A unit of enzyme activity is defined as $1 \mu \mathrm{mol}$ of xanthine oxidized/min, as described by the above authors. Protein was determined by the method of Lowry et al. (1951).

\section{Enzyme assay}

Enzyme activity was measured by the colorimetic method of Owen (1971), with the following modifications: The final assay conditions were adjusted to maintain the enzyme activity linear with respect to time for more than $5 \mathrm{~min}$. The assay mixture, in a final volume of $5 \mathrm{ml}$, contained, in a Thunberg tube: $1 \mathrm{ml}$ of phosphate buffer, $\mathrm{pH} 7.4,500 \mu \mathrm{mol} ; 2,3,5-$ triphenyltetrazolium chloride, $5 \mu \mathrm{mol} ; 0.05 \mathrm{ml}$ of the diluted enzyme and different concentrations of 6-mercaptopurine and $\mathrm{Cu}^{2+}$ as indicated. Into the lid was placed xanthine $(1 \mu \mathrm{mol})$. The tubes were evacuated, filled with $\mathrm{N}_{2}$, and the contents of the tube and the lid were mixed to initiate the reaction. Acetic acid was added to terminate the reaction after $5 \mathrm{~min}$ incubation at $37^{\circ} \mathrm{C}$. The formazan produced was extracted with toluene and the $A_{495}$ measured. A $\Delta A_{495}$ of $0.1 / \mathrm{min}$ corresponded to 1 unit of enzyme activity.

\section{Absorption spectra}

The absorption spectra of 6-mercaptopurine and 6-mercaptopurine- $\mathrm{Cu}^{2+}$ complex were recorded with a Beckman spectrophotometer, model DU2400. All cuvettes used had a $1 \mathrm{~cm}$ light-path.

\section{Stoichiometry}

Job's (1928) method of continuous variation with equimolar solutions of the reagents was used to determine the stoichiometry of the complex. A number of series of solutions were prepared, each with a different concentration of $\mathrm{Cu}^{2+}$ and 6mercaptopurine. Since the maximum difference in the absorbance between 6-mercaptopurine and 6-mercaptopurine- $\mathrm{Cu}^{2+}$ complex was observed at $318 \mathrm{~nm}$, this wavelength was used to record the absorbances of the solutions. Absorbance was also recorded for the same number of 6-mercaptopurine solutions, used as blanks, which were prepared under identical conditions except for the addition of the metal. The difference in the absorbance of each of the above solutions and the corresponding blank was plotted against the molar fraction of copper to obtain 'Job's (1928) curves'.

\section{Stability constant}

The stability constant $(K)$ was calculated from Job's (1928) curves by the method of Subhrama Rao \& Raghav Rao (1955), by employing the formula:

$$
K=(1-\alpha) / \alpha^{2} C
$$

where $C$ is the total concentration of the complex in nmol/litre and $\alpha$ is the degree of dissociation was calculated by the formula:

$$
A_{\mathrm{m}}-A_{\mathrm{s}} / A_{\mathrm{m}}
$$

where $A_{\mathrm{m}}$ is the maximum absorbance obtained from the horizontal portion of the curve, indicating that all reagent is present in the form of chelate. $A_{\mathrm{s}}$ is the absorbance at the stoichiometric molar ratio of the complex, the total concentration of the complex being equal to the concentration of the reagent.

\section{Results and discussion}

Incubation of xanthine oxidase with various concentrations of 6-mercaptopurine produced a slight activation of the enzyme activity at low concentrations of the purine. Control experiments, performed simultaneously in the absence of xanthine, did not reveal any substrate activity of 6-mercaptopurine at these concentrations of the purine. Increasing the concentration of 6-mercaptopurine, however, resulted in the inhibition of the enzyme, as seen from Fig. 1.

Xanthine oxidase was markedly inactivated by $\mathrm{Cu}^{2+}$ (Fig. 1). A definite inhibition of the enzyme activity was observed with concentrations of $\mathrm{Cu}^{2+}$ as low as $5 \mu \mathrm{M}$, whereas maximal inhibition $(96.7 \%)$

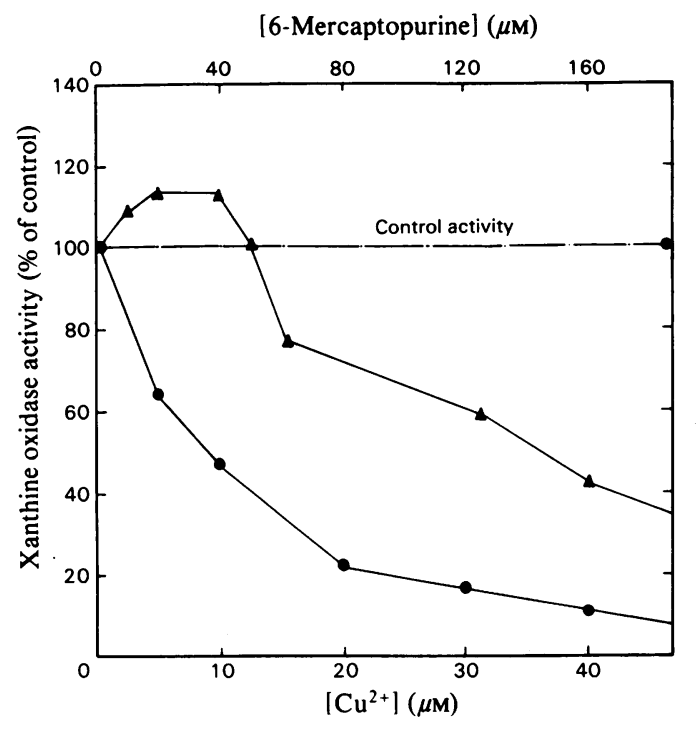

Fig. 1. Concentration-dependence of the alteration of xanthine oxidase activity by 6-mercaptopurine and $\mathrm{Cu}^{2+}$

Each point represents the final activity obtained in an incubation mixture under the conditions described in the Materials and methods section. $P$, $\mathrm{Cu}^{2+}$ at the concentration shown on the lower scale; $\Delta, 6$-mercaptopurine at the concentration shown on the upper scale. 
was produced by $50 \mu \mathrm{M}-\mathrm{Cu}^{2+}$. The Lineweaver-Burk (1934) plots in the absence and presence of $\mathrm{Cu}^{2+}$ revealed the inhibition to be non-competitive. The apparent $K_{\mathrm{i}}$ value calculated from these data was found to be $9 \times 10^{-6} \mathrm{M}$.

Since in our previous work with pyruvate kinase (Vijayvargiya et al., 1970) it was observed that D-penicillamine, a thiol compound with known anti-inflammatory activity, could protect against as well as reverse the inhibition of the enzyme by $\mathrm{Cu}^{2+}$, we tried to examine whether such a relationship holds good or not with 6-mercaptopurine and $\mathrm{Cu}^{2+}$-inhibited xanthine oxidase. Table 1 demonstrates that the addition of 6-mercaptopurine $(20 \mu \mathrm{M})$ after the addition of low concentrations of $\mathrm{Cu}^{2+}$ $(5 \mu \mathrm{M})$ led to complete protection of the enzyme against $\mathrm{Cu}^{2+}$ inhibition. 6-Mercaptopurine, however also provided protection of the enzyme against the inhibition produced by higher concentrations of this cation.

The possibility that 6-mercaptopurine treatment could also effect the re-activation of $\mathrm{Cu}^{2+}$-inactivated xanthine oxidase was further investigated. The results (Fig. 2) demonstrate that preincubation of the enzyme for $10 \mathrm{~min}$ with $2.5-10 \mu \mathrm{M}-\mathrm{Cu}^{2+}$ markedly decreased the activity of xanthine oxidase. When 6-mercaptopurine was added to the incubation mixture, the inhibition observed wtih the lower concentrations of $\mathrm{Cu}^{2+}$ was reversed. 6-Mercaptopurine, however, failed to produce complete reversal of the enzyme inhibition at higher concentrations of $\mathrm{Cu}^{2+}$. The data thus indicate the possibility of irreversible inactivation of the enzyme by copper.

During the course of the above experiments it was observed that, on the addition of 6-mercaptopurine to the reaction mixture containing $\mathrm{Cu}^{2+}$, a spontaneous change from colourless to a yellow colour occurred. This indicated the possibility of complex-formation between 6-mercaptopurine molecules and $\mathrm{Cu}^{2+}$ ions. In order to confirm the formation of the complex, absorption spectra of 6-mercaptopurine and 6-mercaptopurine- $\mathrm{Cu}^{2+} \mathrm{com}$ - plex were compared by recording their absorbance at $\mathrm{pH} 8.0$ between 250 and $350 \mathrm{~nm}$. A characteristic alteration in the absorption spectrum of 6-mercaptopurine was observed when equimolar solutions of 6-mercaptopurine and $\mathrm{Cu}^{2+}$ (as $\mathrm{CuSO}_{4}$ ) were mixed. The maximum absorption by 6-mercaptopurine was observed at $318 \mathrm{~nm}$, whereas no such peak could be detected for the complex. Moreover, the absorption by 6-mercaptopurine was much more than that by the 6 -mercaptopurine- $\mathrm{Cu}^{2+}$ complex, the maximum difference being at $318 \mathrm{~nm}$.

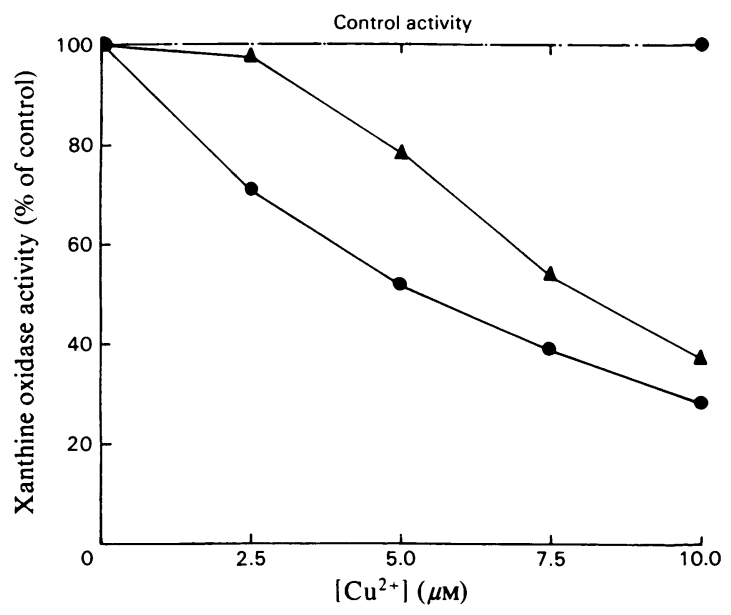

Fig. 2. Reversal by 6-mercaptopurine of xanthine oxidase inhibition by $\mathrm{Cu}^{2+}$

A sample $(0.4 \mathrm{ml})$ of purified diluted enzyme was preincubated on ice for $10 \mathrm{~min}$ with $0.4 \mathrm{ml}$ of $\mathrm{Cu}^{2+}$ - $(2.5-10 \mu \mathrm{M})$. A $0.2 \mathrm{ml}$ portion was withdrawn from the preincubation mixture and mixed with $0.2 \mathrm{ml}$ of either water or 6 -mercaptopurine $(20 \mu \mathrm{M})$, and this was then used for assaying xanthine oxidase activity. - Without 6-mercaptopurine treatment; $\boldsymbol{\Delta}$, 6-mercaptopurine-treated enzyme.

Table 1. Protective action of 6-mercaptopurine against $\mathrm{Cu}^{2+}$ inhibition of xanthine oxidase $\mathrm{Cu}^{2+}$ (at three different concentrations) was added to the reaction mixture just before the addition of 6-mercaptopurine $(20 \mu \mathrm{M})$. Each value is the average for three separate experiments.

\begin{tabular}{lcc}
\multicolumn{1}{c}{$\begin{array}{c}\text { Addition } \\
\text { None (Control) }\end{array}$} & Concn. $(\mu \mathrm{M})$ & $\begin{array}{c}\text { Xanthine oxidase activity } \\
(\% \text { of control) }\end{array}$ \\
6-Mercaptopurine & 20 & 100.0 \\
$\mathrm{Cu}^{2+}$ & 5 & 114.0 \\
& 10 & 64.1 \\
$\mathrm{Cu}^{2+}+$ 6-mercaptopurine & 20 & 47.0 \\
& $5+20$ & 22.7 \\
& $10+20$ & 103.0 \\
& $20+20$ & 84.2 \\
& & 82.6
\end{tabular}




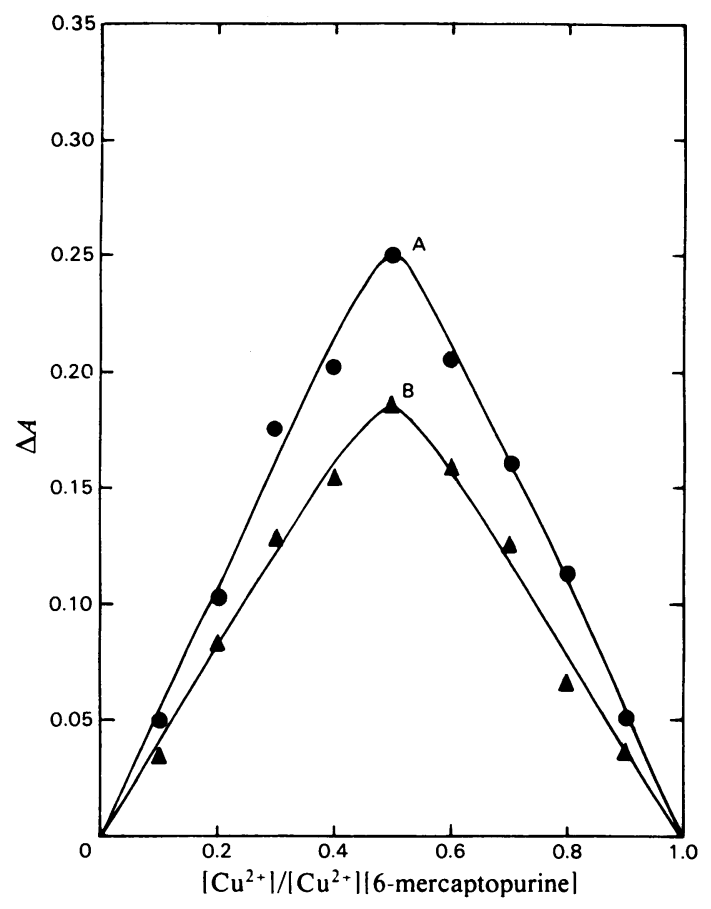

Fig. 3. Job's (1928) curves (equimolar) Concentrations of the reagents: A, [6-mercaptopurine $]=\left[\mathrm{Cu}^{2+}\right]=20 \mu \mathrm{M} ; \quad \mathrm{B}, \quad$ [6-mercaptopurine $]=\left[\mathrm{Cu}^{2+}\right]=16.6 \mu \mathrm{M}$. The values are averages for six separate experiments.

The stoichiometry of the complex, as determined by Job's (1928) method of continuous variation with equimolar solutions of the reagents is presented in Fig. 3. It is evident from these curves that $\mathrm{Cu}^{2+}$ forms a $1: 1$ complex with 6-mercaptopurine. The apparent stability constant $(\log K)$, as calculated by Subhrama Rao \& Raghav Rao's (1955) method is found to be 6.74 (S.E.M. \pm 0.04 ).

The effect of the 1:1 6-mercaptopurine- $\mathrm{Cu}^{2+}$ complex on the enzyme activity was then studied (Table 2). Different concentrations of the complex did not produce as large a decrease in the xanthine oxidase activity as did similar concentrations of free $\mathrm{Cu}^{2+}$. The extent of inhibition was similar to that caused by 6-mercaptopurine alone (Fig. 1).

Our results have revealed $\mathrm{Cu}^{2+}$ to be an inhibitor as well as an inactivator of xanthine oxidase. In addition it exhibited the ability of forming a complex with 6-mercaptopurine. The mechanism by which 6-mercaptopurine protects and reverses copper inhibition of the enzyme activity thus becomes explainable by the process of chelation of $\mathrm{Cu}^{2+}$ ions by the drug. The physiological significance of the inhibition of xanthine oxidase by copper could be interpreted in terms of the regulation of the enzyme activity by the metal. It can further be suggested that
Table 2. Effect of $\mathrm{Cu}^{2+}-6$-mercaptopurine complex $(1: 1)$ on xanthine oxidase activity

Different concentrations of 6-mercaptopurine and $\mathrm{Cu}^{2+}$ solutions were mixed in $1: 1$ proportion and placed in the incubation mixture before the addition of xanthine.

$\begin{array}{cc}{\left[\mathrm{Cu}^{2+}-6 \text {-mercaptopurine] }\right.} & \begin{array}{c}\text { Xanthine oxidase activity } \\ (\% \text { of control) }\end{array} \\ 0.01 & 94.0 \\ 0.02 & 93.1 \\ 0.04 & 87.2 \\ 0.06 & 83.5\end{array}$

the reported decreased xanthine oxidase activity in neoplastic cells (Prajda et al., 1976; Weber, 1973) may be related with the inactivation of the enzyme by the element.

Since formation of the copper complex of antiinflammatory drugs has been shown to be associated with the mechanism of their action (Elmes, 1974), a similar process in the anti-inflammatory action of 6-mercaptopurine can be considered. Moreover, in addition to the described anti-metabolite action of 6-mercaptopurine in neoplastic disorders, it might also aid in the treatment of the disease by chelating copper, as a decrease in the concentration of copper is reported to be an index of the chemotherapeutic benefit of the degree of malignancy (Hrgovcic et al., 1968). Furthermore, the stability constant of the copper-6-mercaptopurine complex is found to exceed those of several naturally occuring cellular chelators for copper (Bjerrum et al., 1957; Foye, 1961). The magnitude of the stability constant thus provides a satisfactory indication for the proposed mechanism of action of 6-mercaptopurine as a drug. In conclusion, we believe that the above process can be an additional mechanism of action of 6-mercaptopurine hitherto not described.

We are grateful to the University Grants Commission, New Delhi, India, for their financial assistance and to the Dean of the M.G.M. Medical College, Indore, India, for providing the necessary facilities. U. K. is a lecturer in biochemistry at the Holkar Science College, Indore452001.

\section{References}

Bean, R. H. D. (1966) Br. Med. J. i, 1081-1084

Bergel, F. \& Bray, R. C. (1959) Biochem. J. 73, 182-192

Bjerrum, J., Schwarzenbach, G. \& Sillen, L. G. (1957) Stability Constants, Part I: Organic Ligands, The Chemical Society, London

Calabresi, P. \& Parks, R. E., Jr. (1975) in The Pharmacological Basis of Therapeutics (Goodman, L. S. \& Gilman, A., eds.), 5th edn., pp. 1254-1307, Macmillan, New York

Elmes, M. E. (1974) Lancet ii, 1329-1330 
Fleming, C. R., Dickson, E. R., Baggenstoss, A. H. \& McCall, J. T. (1974) Gastroenterology 67, 1182-1187

Foye, W. O. (1961) J. Pharm. Sci. 50, 93-108

Hitchings, G. H. \& Elion, G. B. (1963) Pharmacol. Rev. 15, 365-405

Hrgovcic, M., Tessmer, C. F., Minckler, T. M., Mosier, B. \& Taylor, G. H. (1968) Cancer 21, 743-755

Hrgovcic, M., Tessmer, C. F., Thomas, F. B., Ong, P. S., Gramble, J. F. \& Schullenburger, G. C. (1973) Cancer 32, 1512-1524

Job, P. (1928) Ann. Chim. 9, 113-203

Lineweaver, H. \& Burk, D. (1934) J. Am. Chem. Soc. 56, 658-666

Lorenzen, I. \& Videbaek, A. (1965) Lancet ii, 558-561
Lowry, O. H., Rosebrough, N. J., Farr, A. L. \& Randall, R. J. (1951) J. Biol. Chem. 193, 265-275

Massey, V., Brumby, P. E., Komai, H. \& Palmer, G. (1969) J. Biol. Chem. 244, 1682-1691

Owen, E. C. (1971) Methods Enzymol 18B, 590-592

Page, A. R., Condie, R. M. \& Good, R. A. (1962) Am. J. Pathol. 40, 519-527

Prajda, N., Morris, H. P. \& Weber, G. (1976) Cancer Res. 36, 4639-4646

Subhrama Rao, K. V. \& Raghav Rao, S. V. (1955) J. Sci. Ind. Res. 14-B, 278-281

Vijayvargiya, R., Schwark, W. S. \& Singhal, R. L. (1970) Can. J. Biochem. 48, 1268-1277

Weber, G. (1973) Adv. Enzyme Regul. 11, 79-102 